Article

\title{
An Evaluation of Air Transport Sector Operational Efficiency in China based on a Three-Stage DEA Analysis
}

\author{
Mingli Song ${ }^{1}$, Guangshe Jia ${ }^{1}$ and Puwei Zhang ${ }^{2, * \mathbb{D}}$ \\ 1 School of Economics and Management, Tongji University, Shanghai 200092, China; \\ 1610316@tongji.edu.cn (M.S.); jiagsh801@tongji.edu.cn (G.J.) \\ 2 College of City Construction, Jiangxi Normal University, Nanchang 330022, China \\ * Correspondence: zhang.p.w@jxnu.edu.cn
}

Received: 23 April 2020; Accepted: 19 May 2020; Published: 21 May 2020

check for updates

\begin{abstract}
Air transport provides important transportation services for economic development; meanwhile, its operation requires massive resource inputs into the air transport sector (ATS). In order to ensure sustainable development of air transport industry, improve the utilization efficiency of resources, and coordinate the development of the ATS and the macroeconomy, the operational efficiency of the industry should be evaluated accurately. However, few studies have analyzed the operational performance of ATSs across different regions. This study therefore constructs an index system and applied a three-stage data envelopment analysis (DEA) approach, which considers various regional environmental factors and statistical noise, to evaluate regional ATS operational performance. China's 30 provincial ATS operational efficiencies in year 2017 are empirically evaluated using the proposed model. The empirical results show that different levels of environmental factors, such as regional GDP, openness, technical markets, technological development, and consumption, pose various influences on provincial ATS operational efficiency in China. Operational performance evaluation results eliminating these environmental effects in the third stage show considerable differences with that stage 1 results. In addition, corresponding development strategy implications in different provinces and regions are put forward according to the evaluation results.
\end{abstract}

Keywords: air transport sector; operational performance; three-stage data envelopment analysis; regional efficiency

\section{Introduction}

Air transport generates benefits to passengers, shippers, and the wider economy by providing speedy connections between cities, which enable the flows of goods, investments, people, and ideas that drive the economic growth. According to the International Air Transport Association (IATA), in 2017, 557 million passenger journeys in China were carried out by air transport, which accounted for a majority of air passenger journeys worldwide. Additionally, China's air transport sector (ATS), including airlines, airport operators, airport on-site enterprises, aircraft maintenance, and air navigation service providers, is estimated to support US \$104 billion of the national GDP. China's air transport market is forecast to grow by $173 \%$ in the next 20 years, which will bring 1519 million passenger journeys in 2037.

Rapid expansion of air transportation is accompanied by a large amount of resource inputs. Although the air transport industry provides services with public goods attributes and significant externalities, problems can rise when its development is carried out at excessive costs, or in an inefficient and unproductive way [1]. As the importance of an efficient use of public resources and high-quality 
fiscal policies for economic growth and stability has been brought to the forefront, the adequate measurement of such public sectors' efficiency becomes an essential problem but the literature on it is rather scarce [2]. The operational efficiency of transport sectors should have a significant impact on future transportation planning and the budgets of central and local governments [3]. Considering the fact that air transport is such a capital-intensive sector and is often heavily subsidized in many countries, it is necessary to frame an economic efficiency evaluation into a transport planning perspective, to help conduct a forward-looking planning processes, and to ensure the utilization efficiency of the resources invested into the industry. Meanwhile, since air transport sectors in various regions are affected by different external macroeconomic and social environment factors, the "real" efficiency of inter-regional air transport can be evaluated correctly only on the premise of taking these external factors into consideration, in order to provide references for future sustainable development of the industry.

In practice, China's aviation authorities have recognized the importance of enhancing the resource utilization efficiency and expanding air transport in a fiscally responsible manner. China's Strategic Plan for Civil Aviation Development (Civil Aviation Authority of China, 2016) has emphasized improving the efficiency of the whole air transport sector and ensuring its sustainable development across different regions. Additionally, it is necessary for air transport administrations to benchmark each region's ATS production performance in order to determine resource utilization efficiency, find the efficient regions, propose improvement directions for less efficient regions, and support air transport development strategy. Besides, performance evaluation results of ATS can also help ATS participants, such as airlines, airport operators, air traffic control, airport on-site enterprises, aircraft maintenance and air navigation service providers with their investment decisions. For example, airports in different regions in China are requested to prove the eligibility and feasibility to expand infrastructure capacity, because of the vast resource input demand, competition among airports for additional capacity, and the regulatory laws by which the air transport industry operates. Assessment of ATS performance would appear to help provide answers to such concerns. With aforementioned theoretical and practical concerns in mind, the measurement and analysis of air transport sector efficiency and the productivity changes of the 30 provinces across China has become the research objective of this paper.

There are many data envelopment analysis (DEA)-based efficiency studies in the field of civil aviation, as improving operational efficiency has become the management focus of many airlines, airport companies, and civil aviation administrations. The Malmquist productivity index was applied to analyze the operational efficiency of Turkey airports using panel data [4]. Previous literatures also applied the network DEA (NDEA) model, which considers undesirable outputs and intermediate product, to model and benchmark Spanish airport operations [5], East Asia airports [6], and European airlines [7]. The authors of [8] used a dynamic by-production model to measure the dynamic efficiencies of airlines considering the requirement of carbon emission reduction. Another kind of relevant research literature focused on air transport networks (ATNs) comprises multi-airports as well as flights between them as research objects, and evaluates the efficiency and robustness of ATNs [9-11]. Previous studies mostly focused on the efficiency evaluation of airports or airlines, or on some more comprehensive objects such as ATNs. However, all participants in the air transport sector work together to ensure air transport performance and its sustainable development. To improve ATS's comprehensive benefits and ensure its sustainable development, it is necessary to evaluate and improve the efficiency of the whole ATS [12,13]. Though entire-industry efficiency studies have drawn much research attention in other sectors, studies on the operational performance of the overall air transport sector are still extremely scant. This is probably because of the lack of appropriate indicators and data for ATS efficiency evaluation.

Another defect of previous air transport industry performance studies is that few of them considered the impact of various exogenous economic and social factors in different regions. Some literatures on airport efficiency have used DEA model combined with a second-stage regression to identify some endogenous factors affecting airport performance, such as location, hub status, and degree of privatization $[14,15]$. However, few literatures have considered the exogenous socio-economic 
factors that are beyond the management control of airports or outside of the airport industry itself [16]. However, such exogenous socio-economic factors have been argued to actually influence the air transport performance and efficiency in various ways. For example, 17 national macro-environmental factors such as innovation, living standards of citizen, technological readiness, financial market development, macro-economic environment, and goods market efficiency were proposed to influence regional air transport volume and performance [16]. The economic and social effects of the population have been considered as environmental factors that influence the performance of Spanish and Turkish airports [17].

Three-stage data envelopment analysis (DEA) [18] is an efficiency evaluation method that can account for environmental effects and statistical noise, and has been used in efficiency evaluation in a range of industries, such as hotel management $[19,20]$, the banking industry [21], the cultural industry [22], and the electric power industry [23]. This model was also applied to study energy efficiency in the manufacturing sector [24], construction sector [25], transportation sector [26], and the overall economy [27]. However, few studies applied this method to efficiency evaluation in the civil aviation industry. To fill the above-mentioned gap in ATS performance researches, this study applies the Fried three-stage DEA method and constructs the corresponding input-output and environmental indexes, so as to evaluate China's provincial ATS efficiency while considering social and economic environments of different regions.

It is worth noting here that previous to the three-stage method, Fried et al. [28] proposed a similar four-stage DEA-based method that can account for environmental factors, which has also been applied in industrial efficiency analysis, such as in the service sectors [29]. Both methods firstly carry out the traditional DEA analysis and then use the slacks obtained by the first stage of the DEA analysis to calculate the environmental impact and adjust the input or output by using an econometric model. Finally, the adjusted input or output data are used for DEA analysis. Formally, in the 2002 paper, Fried et al. combined the second stage, which can identify the influences of operating environment factors on the inefficiency, and the third stage, which aims to predict the total input slack or output surplus and calculate the adjusted input or output values, of the four-stage method in the 1999 paper into one stage (the second stage) of the three-stage method. The more substantial difference between the two methods is that, in the second stage in the 1999 paper, the equations used to quantify the effect of external conditions on the excessive use of inputs can be the specified according to the econometric technique that is adopted, such as ordinary least squares (OLS), a Tobit model, or a seemingly unrelated regression (SUR) system; while the Fried three-stage method [18], in particular, adopts stochastic frontier analysis (SFA) to regress first stage slacks against a set of environmental variables in the second stage. The shortcoming of the four-stage method [28] approach is that the data adjustment accounts for environmental impacts, but not for the impact of statistical noise [18]. Additionally, that is the reason why in the second stage of the three-stage approach, SFA is used to attribute variations in the first stage producer performance to environmental effects, managerial inefficiency, and statistical noise. Therefore, the third-stage method [18] can be viewed as an extension and a special case of the four-stage method [28].

The remainder of the paper is structured as follows. Section 2 presents a brief introduction to the methodology applied in this research. Section 3 describes the indicators and data sources, including the input, output and environmental variables. The empirical results are presented in Section 4. Section 5 is the discussion.

\section{Methods}

This research applies the three-stage DEA-based approach proposed by Fried et al. [18] to evaluate operational performance of air transport sector. At the first stage, the initial efficiency based on variable returns to scale (VRS) is evaluated with a Banker, Charnes, and Cooper's DEA (abbreviated as BCC model based on the names of its proposers) analysis [30], using input and output quantity data only. 
The BCC model is modified from the Charnes, Cooper, and Rhodes' linear program [31] (abbreviated as CCR model based on the names of its proposers). The CCR linear programming formula can be expressed as Equation (1):

$$
\begin{gathered}
\min \theta \\
\text { s.t. } \\
\sum_{j=1}^{n} \lambda_{j} x_{i j} \leq \theta x_{i k} \\
\sum_{j=1}^{n} \lambda_{j} y_{r j} \geq y_{r k} \\
\lambda \geq 0 ; i=1,2, \ldots, m ; r=1,2, \ldots, q ; j=1,2, \ldots, n ;
\end{gathered}
$$

where $x_{i j}$ is the amount of $i$ th input to unit $j, y_{r j}$ is the amount of $r$ th output from unit $j, n$ is the number of decision making units (DMU), $m$ is the number of inputs, and $q$ is the number of outputs. $x_{i k}$ and $y_{r k}$ are the $i$ th input and $r$ th output of the $\mathrm{DMU}_{\mathrm{k}}$ being evaluated, respectively. $\lambda_{j}$ is the $j$ dimensional weight vector of the $\mathrm{DMU}_{\mathrm{j}}$. The CCR optimal solution value indicates the estimation of technical efficiency (TE) of the DMUs.

Compared with the CCR model, which is based on constant returns to scale (CRS), the BCC model only adds the convexity constraint of $\sum_{j=1}^{n} \lambda_{j}=1$, which allows it take VRS into consideration. Since our concern is the extent to which resource inputs can be reduced in order to achieve technical efficiency without any reduction in air transport capacity, the input orientation BCC DEA model was adopted. The BCC model can be expressed as Equation (2):

$$
\begin{gathered}
\min \theta \\
\text { s.t. } \\
\sum_{j=1}^{n} \lambda_{j} x_{i j} \leq \theta x_{i k} \\
\sum_{j=1}^{n} \lambda_{j} y_{r j} \geq y_{r k} \\
\sum_{j=1}^{n} \lambda_{j}=1 \\
\lambda \geq 0 ; i=1,2, \ldots, m ; r=1,2, \ldots, q ; j=1,2, \ldots, n ;
\end{gathered}
$$

The $\theta^{\prime} s$ objective value of the liner program (2) indicates the pure technical efficiency (PTE). Based on the TE value calculated from the CCR linear program and the PTE value from the BCC model, scale efficiency (SE) can be calculated by $S E=T E / P T E$.

According to Banker and Thrall [32], under the setting of multiple-input-multiple-output and multiple optimal solutions, the following procedure can be employed to estimate returns to scale of each DMU in the BCC model. Let $\lambda^{*}$ be the optimal vector for the CCR linear program specified in (1), if $S E=1$, then constant returns to scale (CRS) prevail at $\mathrm{DMU}_{\mathrm{k}}$. If $S E<1$ and $\sum_{j=1}^{n} \lambda_{j}^{*}=1$ in some optimal solutions, then increasing returns to scale (IRS) prevails at $\mathrm{DMU}_{\mathrm{k}}$. If $S E>1$ and $\sum_{j=1}^{n} \lambda_{j}^{*}>1$ in some optimal solutions, then decreasing returns to scale (DRS) prevails at $\mathrm{DMU}_{\mathrm{k}}$. Note here that the CCR model is used only for the separation of scale efficiency and the estimation of the DMUs' returns to scale. Due to the assumption of various returns to scale in this research, in the first and third stages of the three-stage model in this research, the BCC DEA model was employed to evaluate the ATS efficiency.

Subsequently, the quantities of $i$ th input factor's total slack (radial plus non-radial) to unit $j, s_{i j}$ can be gained from the results of the BCC model in the first stage. $s_{i j}$ illustrates the difference between the existing inputs and the ideal inputs to achieve the optimum operational efficiency of each DMU. 
At the second stage, the input slacks $s_{i j}$ gained from the first stage BCC analysis are regressed against observable environmental variables and a composed error term by stochastic frontier approach (SFA) regression analysis. In such an SFA regression model, the regression equations can be expressed as Equation (3):

$$
\begin{gathered}
s_{i j}=f\left(Z_{j}, \beta_{i}\right)+u_{i j}+v_{i j} \\
\varepsilon_{i j}=u_{i j}+v_{i j}
\end{gathered}
$$

where $Z_{j}$ is a vector representing the $t$ environmental variables of the $j$ th DMU, $Z_{j}=\left(z_{1 j}, z_{2 j}, \ldots, z_{t j}\right)$. $\beta_{i}$ is the coefficient vector of the environmental variable. $f\left(Z_{j}, \beta_{i}\right)=Z_{j} \times \beta_{i}$ can calculate the environmental values that affect each DMU's inputs, $\varepsilon_{i j}=u_{i j}+v_{i j}$ is the composed error term, $u_{i j}$ and $v_{i j}$ are uncorrelated variables, $u_{i j}$ reflects the managerial inefficiency component for the $i$ th input of the $j$ th DMU and $u_{i j} \sim N^{+}\left(0, \sigma_{u i}{ }^{2}\right)$, and $v_{i j}$ reflects statistical noise for the $i$ th input of the $j$ th DMU and $v_{i j} \sim N\left(0, \sigma_{v i}{ }^{2}\right)$. Therefore, through the stochastic frontier analysis (SFA), the slacks obtained in the first stage are decomposed into three components, namely environmental influences, managerial inefficiencies, and statistical noise.

Using the results of SFA, each DMU's adjusted inputs can be calculated by Equation (4):

$$
x_{i j}^{A}=x_{i j}+\left[\max _{i}\left(Z_{j} \times \hat{\beta}_{i}\right)-Z_{j} \times \hat{\beta}_{i}\right]+\left[\max _{i}\left(\hat{v}_{i j}\right)-\hat{v}_{i j}\right]
$$

where $x_{i j}^{A}$ and $x_{i j}$ are adjusted and observed input variable values, respectively, and $\hat{\beta}_{i}$ is the estimated values for $\beta_{i}$ obtained by the SFA analysis. On the right side of Equation (4), $\left[\max _{i}\left(Z_{j} \times \hat{\beta}_{i}\right)-Z_{j} \times \hat{\beta}_{i}\right]$ levels the operating environments of all DMUs, and $\left[\max _{i}\left(\hat{v}_{i j}\right)-\hat{v}_{i j}\right]$ puts all DMUs into the similar "luck". In order to obtain estimates of $\hat{v}_{i j}$ for each DMU, according to the methodology of Jondrow et al. [33] and Fried et al. [18], estimators of statistical noise residual can be calculated by Equation (5):

$$
\hat{E}\left[v_{i j} \mid u_{i j}+v_{i j}\right]=s_{i j}-Z_{j} \times \hat{\beta}_{i}-\hat{E}\left[u_{i j} \mid u_{i j}+v_{i j}\right]
$$

where the estimators for managerial inefficiency are given by $\hat{E}\left[u_{i j} \mid u_{i j}+v_{i j}\right]$. Then, adjusted inputs can be obtained by Equation (6):

$$
x_{i j}^{A}=x_{i j}+\left[\max _{i}\left(Z_{j} \times \hat{\beta}_{i}\right)-Z_{j} \times \hat{\beta}_{i}\right]+\left[\max _{i}\left(\hat{E}\left[v_{i j} \mid u_{i j}+v_{i j}\right]\right)-\hat{E}\left[u_{i j} \mid u_{i j}+v_{i j}\right]\right]
$$

In stage 3, using adjusted input data, BCC DEA is performed again to evaluate the "real" operational performance, removing the effects of environmental factors and statistical noise.

\section{Data}

In this research, the DMUs of the DEA model refer to China's 30 provincial ATSs. Consistent with China's Industrial Classification for National Economic Activities (GB/T 4754-2017), the air transport sector in this paper consists of air passenger and freight transport and general aviation services, plus air transport support activities, which include airports, air traffic control, and other air transport auxiliary activities, as shown in Figure 1. The important fact to note here is that according to accounting standards in ATS, the major investments in the air transport industry, such as the purchase of an aircraft fleet by airlines, and the construction of airports and related facilities, are listed as fixed asset investments, which will serve as an important basis for our selection of input indicators later. 


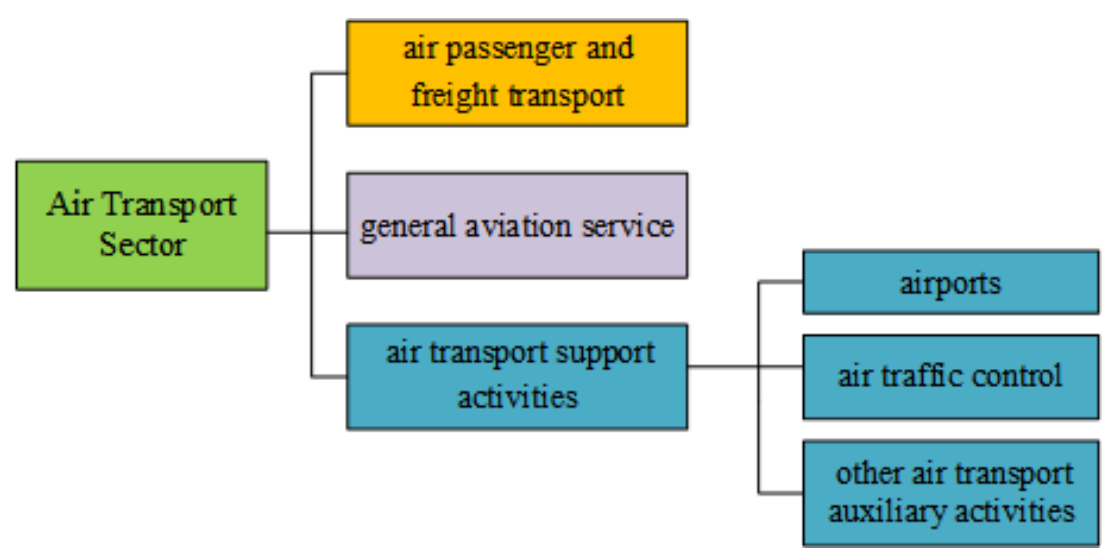

Figure 1. Components of the air transport sector (ATS).

The index system including inputs, outputs, and external factors developed for the three-stage approach is shown in Table 1.

Table 1. Input, output and environmental factors specified for the three-stage approach.

\begin{tabular}{ccc}
\hline Input Indicators & Output Indicators & Environmental Variables \\
\hline Capital Stock & Volume of Passenger & Gross Domestic Product per Capita \\
Number of Employees & Volume of Freight & Actual Utilization of Foreign Direct Investment \\
Infrastructure Construction Level & Aircraft Movements & Transaction Value in Technical Markets \\
& & Three Kinds of patents Granted per 10,000 People \\
& & Household Consumption Expenditure \\
\hline
\end{tabular}

\subsection{Input and Output Indicators}

Inputs in this research are defined as the resources that the air transport sector takes to generate air transport capacity. The capital (rolling stock and infrastructure) and the number of employees (or hours of work) are the mostly considered variables, since they represent the main inputs in the transport industries production process [3].

\subsubsection{Capital Stock}

Air transport is a capital-intensive industry. Investments in infrastructures and aircrafts account for the major part of its input resources. Therefore, it is necessary to accurately measure the capital input to analyze its efficiency. Capital input may be considered as either a flow or a stock variable, since using stock rather than flow can give more robust results and reduce the reverse causality in the empirical models [34]. In previous studies, capital stock was often used as an input indicator. Furthermore, capital stock can be measured in monetary terms or in physical terms; for example, the length, area, or density of road and railway networks [35,36]. However, measuring capital inputs in physical units has been accused of posing several issues, since authors use a vast range of variables and it is quite hard to define a unique unit of measure [3]. Thus, in this research we used the monetary measure of capital stock as an input indicator. However, there is no such indicator in presently available statistics. Hence, we applied the perpetual inventory method [37,38], which is most widely used and considered as the most correct approach in measuring stocks of fixed assets [3], to estimate ATS capital stock in each province. For each province, the net ATS capital stock at the end of current period $K_{t}$ can be calculated by Equation (7):

$$
K_{t}=(1-\delta) K_{t-1}+I_{t}, t=2003,2004, \ldots 2017 .
$$

where $I_{t}$ is the ATS fixed-asset investment in the current period, while $\delta$ is the depreciation rate. Each province's annual data on $I_{t}$ comes from the China Statistical Yearbook of 2003-2018. 
In this research, we assumed ATS capital stock depreciates at a constant rate $\delta$. As to the value of $\delta$, we used the comprehensive China's infrastructure depreciation rate estimated by previous studies [39-41], which is 0.0921 . In addition, according to the perpetual inventory method, the estimation of the initial capital stock $K_{0}$, in our case the capital stock at the end of 2002, is calculated by Equation (8):

$$
K_{0}=\frac{I_{0}}{\delta+g}
$$

where $I_{0}$ is the gross investment in initial year 2002 and $g$ is the geometric average growth rate of fixed asset investment to the ATS between year 2002 and 2012. The value of $g$ is 0.15607 .

\subsubsection{Labor Input}

In terms of labor input, the number of full-time employees in ATS is selected as the indicator. This index shows the number of full-time employees in a province's civil aviation industries, including airlines, airports, air traffic control, and other auxiliary service. Data on this index come from the Year Book of China Transportation and Communications.

\subsubsection{Infrastructure Level}

In this study we propose to construct an indicator that can reflect the level of air transport infrastructure. Specifically, the Federal Aviation Administration (FAA) and International Civil Aviation Organization (ICAO) have both introduced airport design standards [42]. Although the FAA standards are mandatory for airport certification in the US, whereas ICAO standards are adopted by the majority of aviation authorities elsewhere, both standards are very similar in nature and are based on the size of the largest aircraft that is allowed to operate at an airport. Airports are assigned a reference code, which ultimately determines the types of aircraft that the airport can handle [42]. This reference code thus represents the construction level of an airport's airfield and various other airport components. A higher code shows more construction cost in the airport and other aviation support facilities. Thus, the reference code can be used as an infrastructure measurement to reflect the input level of air transport. Due to the application of ICAO standards in Chinese airports, ICAO's aerodrome code is used in this research. It is composed of a number designating the runway length available and a letter representing the size of the aircraft the airport can handle in terms of wingspan and wheel track. The codes and their correspondent runway lengths and aircraft sizes are shown in Table 2.

Table 2. Aerodrome reference codes by International Civil Aviation Organization (ICAO).

\begin{tabular}{ccccc}
\hline $\begin{array}{c}\text { Aerodrome } \\
\text { Code Number }\end{array}$ & $\begin{array}{c}\text { Reference Field } \\
\text { Length }(\mathbf{m})\end{array}$ & $\begin{array}{c}\text { Aerodrome } \\
\text { Code Letter }\end{array}$ & $\begin{array}{c}\text { Wingspan } \\
(\mathbf{m})\end{array}$ & $\begin{array}{c}\text { Outer Main } \\
\text { Gearwheel Span (m) }\end{array}$ \\
\hline 1 & $0-800$ & A & $0-15$ & $0-4.5$ \\
2 & $800-1200$ & B & $15-24$ & $4.5-6$ \\
3 & $1200-1800$ & C & $24-36$ & $6-9$ \\
4 & $\geq 1800$ & D & $36-52$ & $9-14$ \\
& & E & $52-65$ & $9-14$ \\
& & F & $65-80$ & $14-16$ \\
\hline
\end{tabular}

We constructed an infrastructure construction level (ICL) index that reflects both the number and level of airports (LoA) in a province:

$$
I C L_{j}=\sum_{1}^{N_{j}} L o A_{n}, n=1,2, \ldots, N_{j}
$$


where $N_{j}$ is the number of airports in $j$ th province and $L o A_{n}$ is the interval variable constructed based on the ICAO's aerodrome code of each airport in $j$ th province. Specifically, an airport's $\operatorname{Lo} A_{n}=1,2,3,4$ if the airport's ICAO's aerodrome code is $4 \mathrm{C}, 4 \mathrm{D}, 4 \mathrm{E}$, and $4 \mathrm{~F}$, respectively.

\subsection{Output Indicators}

In previous studies, output variables of the transportation sector were mainly classified into two main categories: transportation services (volume of passenger, freight, and vehicles) on one side, and transportation value added (GDP of the sector) on the other [43-45]. Considering that the output value of air transport is not only reflected in GDP in the transportation sector, but also lies in the indirect and catalytic effects of passenger and freight movement on other industries, in this research the volume of passengers, freight, and vehicles were therefore used as three output variables of provincial ATS. Starting from 2017, the Civil Aviation Administration of China (CAAC) has begun to report each province's annual air transport passenger and freight throughput and the aircraft movements volume. Thus, the output data were collected from the CAAC.

\subsection{Environmental Indicators}

The operational efficiency of the air transport sector is also affected by some other economic and social factors, which are referred to as environmental variables in this study. According to previous literatures, it has been theoretically and empirically demonstrated that some social and economic factors affect the demand for air transportation. Firstly, since an increase in economy income leads to an increase in economic activity and boosts the demand for air passenger and freight transport [46], the level of regional income was selected as an environmental variable. Gross domestic product (GDP) per capita was used as a proxy for income. Secondly, because corporations with foreign capital often need air transport to maintain contact with their domestic and foreign organizations, and the production and sales processes of their products and services usually need to be based on air transport, regional openness to foreign investment is related to the air transportation demand and the performance of air transport [47-50]. Therefore, the actual utilization of foreign direct investment (FDI) was selected as an environmental variable. Thirdly, due to the high dependence of R\&D intensive industries, consulting industries, and other "on-time" industries on air transport [51], we chose the transaction value in technical markets (TVTM) as an environmental variable, so as to reflect various development levels of such industries across regions. Fourthly, regional technological readiness is of universal importance to all industries in a region [16], including the air transport sector, and considering high-tech manufacturing companies' dependence on air transport, in this research three kinds of patents granted (TKPG) per 10,000 people was selected as an environmental variable, as the proxy of regional technological readiness. Finally, air transport services have relative high prices in China compared to other modes of transportation, and air transportation is usually associated with high-end consumption on high value-added goods, entertainment, and tourism [52,53]. Therefore, the regional consumption level and living standards will significantly influence air passenger and cargo transport volume $[54,55]$. For this reason, we chose household consumption expenditure (HCE) as the fifth environmental variable. All five environmental variables are posited to influence ATS operational performance. But there is no need to assume the directions of their impacts [18].

The data of input, output, and environmental variables are from the China Statistical Yearbook, the Statistical Yearbook of the Chinese Investment in Fixed Assets, the Year Book of China Transportation and Communications, and statistics released by the Civil Aviation Administration of China (CAAC).

\section{Results}

According to the first stage DEA analysis, the average pure technical efficiency (PTE) and scale efficiency (SE) of 30 provincial ATSs are 0.894 and 0.915 , respectively (Table 3). The PTE of 16 provincial ATSs achieve complete efficiency (the value of PTE equals 1), while 14 provincial ATSs are inefficient (the values of PTE are less than 1). The ATSs of Tianjin, Guangdong, Sichuan, and Qinghai are purely 
technically efficient and scale inefficient (the PTE equals 1 and the SE is smaller than 1). The ATSs of Shandong, Guangdong, Hainan, Sichuan, Yunnan, and Xinjiang are at the phase of decreasing returns to scale (DRS), which illustrates that the growth proportion of output is less than that of input into their ATS. Meanwhile, the other provinces remain at the phase of constant or increasing returns to scale (CRS or IRS), demonstrating that the increment proportion of output equals or exceeds the input scale expansion rate.

Table 3. The first stage and the third stage analysis results.

\begin{tabular}{|c|c|c|c|c|c|c|c|}
\hline \multicolumn{2}{|c|}{ Region } & \multicolumn{3}{|c|}{ The First Stage } & \multicolumn{3}{|c|}{ The Third Stage } \\
\hline & & PTE & SE & Return to Scale & PTE & SE & Return to Scale \\
\hline \multirow{5}{*}{ North China } & Beijing & 1 & 1 & CRS & 1 & 0.955 & IRS \\
\hline & Tianjin & 1 & 0.838 & IRS & 1 & 0.682 & IRS \\
\hline & Hebei & 0.733 & 0.787 & IRS & 0.828 & 0.678 & IRS \\
\hline & Shanxi & 1 & 1 & CRS & 1 & 0.859 & IRS \\
\hline & $\begin{array}{c}\text { Inner } \\
\text { Mongolia }\end{array}$ & 1 & 1 & CRS & 1 & 1 & CRS \\
\hline \multirow{4}{*}{ Northeast China } & Liaoning & 0.678 & 0.975 & IRS & 0.787 & 0.957 & IRS \\
\hline & Jilin & 0.687 & 0.791 & IRS & 0.751 & 0.718 & IRS \\
\hline & Heilongjiang & 0.784 & 0.961 & IRS & 0.863 & 0.871 & IRS \\
\hline & Shanghai & 1 & 1 & CRS & 1 & 1 & CRS \\
\hline \multirow{5}{*}{ East China } & Jiangsu & 1 & 1 & CRS & 1 & 1 & CRS \\
\hline & Zhejiang & 1 & 1 & CRS & 1 & 1 & CRS \\
\hline & Anhui & 0.821 & 0.838 & IRS & 0.817 & 0.69 & IRS \\
\hline & Fujian & 0.751 & 0.995 & IRS & 0.754 & 0.999 & DRS \\
\hline & Jiangxi & 1 & 1 & CRS & 1 & 0.829 & IRS \\
\hline \multirow{8}{*}{$\begin{array}{l}\text { Central and } \\
\text { Southern China }\end{array}$} & Shandong & 0.959 & 0.721 & DRS & 1 & 0.735 & DRS \\
\hline & Henan & 1 & 1 & CRS & 1 & 1 & CRS \\
\hline & Hubei & 0.754 & 0.995 & IRS & 0.799 & 1 & CRS \\
\hline & Hunan & 0.825 & 0.999 & IRS & 0.897 & 0.956 & IRS \\
\hline & Guangdong & 1 & 0.766 & DRS & 1 & 0.777 & DRS \\
\hline & Guangxi & 0.827 & 0.995 & DRS & 0.839 & 0.963 & IRS \\
\hline & Hainan & 0.688 & 0.977 & DRS & 0.743 & 0.99 & DRS \\
\hline & Chongqing & 1 & 1 & CRS & 1 & 1 & CRS \\
\hline \multirow{3}{*}{ Southwest China } & Sichuan & 1 & 0.791 & DRS & 1 & 0.882 & DRS \\
\hline & Guizhou & 0.619 & 0.967 & IRS & 0.651 & 0.947 & IRS \\
\hline & Yunnan & 0.952 & 0.689 & DRS & 1 & 0.695 & DRS \\
\hline \multirow{6}{*}{ Northwest China } & Shannxi & 1 & 1 & CRS & 1 & 1 & CRS \\
\hline & Gansu & 1 & 1 & CRS & 1 & 1 & CRS \\
\hline & Qinghai & 1 & 0.52 & IRS & 1 & 0.496 & IRS \\
\hline & Ningxia & 1 & 1 & CRS & 1 & 0.733 & IRS \\
\hline & Xinjiang & 0.772 & 0.901 & DRS & 0.737 & 0.983 & IRS \\
\hline & Mean & 0.894 & 0.915 & & 0.916 & 0.880 & \\
\hline
\end{tabular}

Note: PTE means the pure technical efficiency; SE means the scale efficiency. IRS, CRS, and DRS represent increasing returns to scale, constant return to scale, and decreasing return to scale, respectively.

At the second stage, the SFA regression was applied to regress slacks of the capital stock (CS), number of employees (NoE), and air transport infrastructure construction level (ICL), respectively, against five environmental variables, including the GDP per capita, actual utilization of FDI, transaction value in technical markets (TVTM), three kinds of patents granted (TKPG) per 10,000 people, and household consumption expenditure (HCE).

The SFA results are shown in Table 4. These results demonstrate the significant influences of the chosen environmental factors on ATS operational efficiency. 
Table 4. The second stage stochastic frontier analysis (SFA) results.

\begin{tabular}{cccc}
\hline \multirow{2}{*}{ Independent Variable } & \multicolumn{3}{c}{ Dependent Variable } \\
\cline { 2 - 4 } & CS Slack & NoE Slack & ICL Slack \\
\hline Constant term & -33.31 & -0.42 & -2.79 \\
& $(-11.07) *$ & $(-3.70)^{*}$ & $(-1.65)$ \\
GDP per capita & 47.26 & -0.40 & 8.07 \\
& $(34.60)^{*}$ & $(-0.59)$ & $(6.47)^{*}$ \\
Actual utilization of FDI & -44.38 & 2.61 & -6.57 \\
Transaction Value in Technical & $(-40.88)^{*}$ & $(12.49)^{*}$ & $(-4.39)^{*}$ \\
Markets (TVTM) & -42.91 & 2.33 & 8.55 \\
Three Kinds of patents Granted & $(-40.60)^{*}$ & $(3.63) *$ & $(5.88)^{*}$ \\
(TKPG) per 10,000 people & 111.69 & 0.41 & 7.07 \\
Household Consumption & $(92.33) *$ & $(0.61)$ & $(5.89)^{*}$ \\
Expenditure (HCE) & -117.64 & -3.49 & -27.29 \\
$\sigma_{i}^{2}$ & $(-97.72) *$ & $(-14.24) *$ & $(-12.07) *$ \\
$\gamma_{i}^{*}$ & 20546.49 & 10.17 & 258.27 \\
LR test of the one-sided error & 0.99999 & 0.99999 & 0.99999 \\
& 24.29 & 19.52 & 13.23 \\
\hline
\end{tabular}

* Significant at the $1 \%$ level or better. Data in brackets represent t-statistics of the coefficients. CS Slack, NoE Slack, and ICL Slack represent the slack of capital stock, number of employees, and air transport infrastructure construction level, respectively.

In accordance with Table 4, likelihood ratio test values of the SFA regressions for all three input slacks are all higher than the threshold value of the mixed chi-square distribution examination and significant under the $1 \%$ confidence level, rejecting the hypothesis that the one-sided error component makes no contribution to the composed error term, implying the rationality of the stochastic frontier specification. And in all three SFA regressions, $\gamma_{i}$ values are close to 1 , indicating the input slacks are mainly attributed to the managerial inefficiency instead of the statistical noise.

By viewing the second row in Table 4, the coefficients under the GDP per capita are positive and significant at the $1 \%$ level in the regressions of CS Slack and ICL Slack (47.26 and 8.07, respectively). Similarly, the third row shows that coefficients under TKPG per 10,000 people are positive and significant at the $1 \%$ level in the regression of CS Slack and ICL Slack (111.69 and 7.07, respectively). Because of the increase of the GDP per capita and technology-intensive industries, air transport demand will increase, resulting in the increase of ATS investments and expansion on airport infrastructure construction. As the inputs increases, it will become more challenging to improve operational performance. Therefore, the increase of GDP per capita and technology-intensive industries may bring about increasing air transport demand, but will not necessarily lead to the improvement of operational efficiency of ATSs. For the number of employees, the coefficients of the GDP per capita and TKPG per 10,000 people $(-0.40$ and 0.41 , respectively) are insignificant at the $1 \%$ level. The negative and significant coefficients of actual utilization of FDI in the regressions of CS Slack and ICL Slack $(-44.38$ and -6.57 , respectively) indicate that more actual utilization of FDI and a higher degree of openness are beneficial to ATSs so as to enhance the utilization of capital input and infrastructure. Similarly, the negative and significant coefficients of household consumption expenditure (HCE) in the regression of the CS Slack and ICL Slack (-117.64 and -27.29 , respectively) show that a higher consumption level is beneficial to ATS operation. The decrease in the input slacks of capital stock and infrastructure construction is attributed to a benevolent environment for ATS supported by vigorous consumption.

The inputs were then adjusted to offset the effects of environmental factors and in statistical noise. To be specific, values of $\sigma_{i}^{2}$ and $\gamma_{i}$ were replaced by Equations (3) and (4), and then the values of three input variables were adjusted by Equation (5). Through this adjustment, provinces with relatively unfavorable ATS operating environments and relatively bad luck had their inputs adjusted upwards, while provinces with relatively favorable operating environments and relatively good luck had their inputs adjusted upwards [18]. 
At the third stage, using the adjusted inputs data, we could estimate the operational performance again with the BCC DEA model. This final evaluation puts all provincial ATSs on a level playing field and can reflect the actual ATS operational performance, since the effects of environmental factors and the statistical noise have been accounted for.

Table 2 listed the polished pure technical efficiency of the 30 provincial air transport sectors. After the adjustment, the mean values of PTE and SE changed from 0.894 and 0.915 to 0.916 and 0.880 , respectively, implying that the effects of environmental factors and statistical noise resulted in the underestimation of PTE and overestimation of SE from an overall perspective. The average PTE score is 0.916 , illustrating that under the VRS assumption, the pure technical efficiency gap is 8.4 percent and the industry could reduce inputs by 8.4 percent $(=1.000-0.916)$ of their current level if the operational practices of the most efficient provincial ATSs (those with PTE scores of 1.000) were applied throughout the industry. The average SE score is 0.880 , suggesting that inputs can be reduced by 4.9 percent through enhancing the scale of the air transport industry using the current best practice.

The ATS PTEs of 12 provinces, including Hebei, Liaoning, Jilin, Heilongjiang, Fujian, Shandong, Hubei, Hunan, Guangxi, Hainan, Guizhou, and Yunnan, increase after eliminating the impacts of environmental factors and statistical noise, indicating that the macroeconomic factors of these provinces exert negative influences on the PTE of ATSs. This result may indicate that these provincial ATSs would be more productive if the administrations take measures to forge an economic and social environment that is more beneficial to air transport. On the contrary, Anhui and Xinjiang have lower PTE after adjustment, demonstrating that they have relatively favorable environments for ATS operation.

The number of the pure technical efficient ATSs, with a PTE that equals 1, became larger in the third stage (18 DMUs) compared to the first stage (16 DMUs). Shandong and Yunnan newly achieved completely pure technical efficiency (at the PTE frontier). Beijing, Shanxi, Jiangxi, and Ningxia became no more scale efficient (with SE values less than 1).

It was further found that after the adjustment, evaluation of the returns to scale of ATS was dramatically altered after controlling for the impacts of the environmental factors and statistical noise. The number of DMUs that operate at the stage of increasing returns to scale (IRS) expanded to 15 from 10 in the third stage, with Beijing, Shanxi, Jiangxi, and Ningxia shifting from CRS (constant returns to scale) to IRS, and Guangxi and Xinjiang shifting from DRS to IRS. Nine provinces are technically inefficient and indicating IRS at the same time, and they should try to improve ATS performance to BCC technical efficiency with increasing returns to scale before additional resource inputs are considered [56]. Tianjin, Shanxi, Jiangxi Qinghai, and Ningxia are BCC efficient while indicating IRS, which means that with additional resource inputs, ATS in these provinces can generate outputs under most productive scale size (MPSS) if they can keep away from falling into a region of being inefficient at CRS. With Fujian going from IRS to DRS in the third stage, six provinces are identified as operating with DRS, which indicates that their ATS is being overcapitalized and spending more resource inputs than required to generate outputs.

The CAAC has divided the civil aviation of China into six regions, including North China, Northeast China, East China, Central and Southern China, Southwest China, and Northwest China, and has set up regional administration for each region. By calculating the mean PTE value of each region, it was found that the ATS PTE of North China, East China, and Northwest China goes lower by the third stage evaluation than by the first stage, indicating these regions have a favorable environment for ATS operation (Figure 2). 


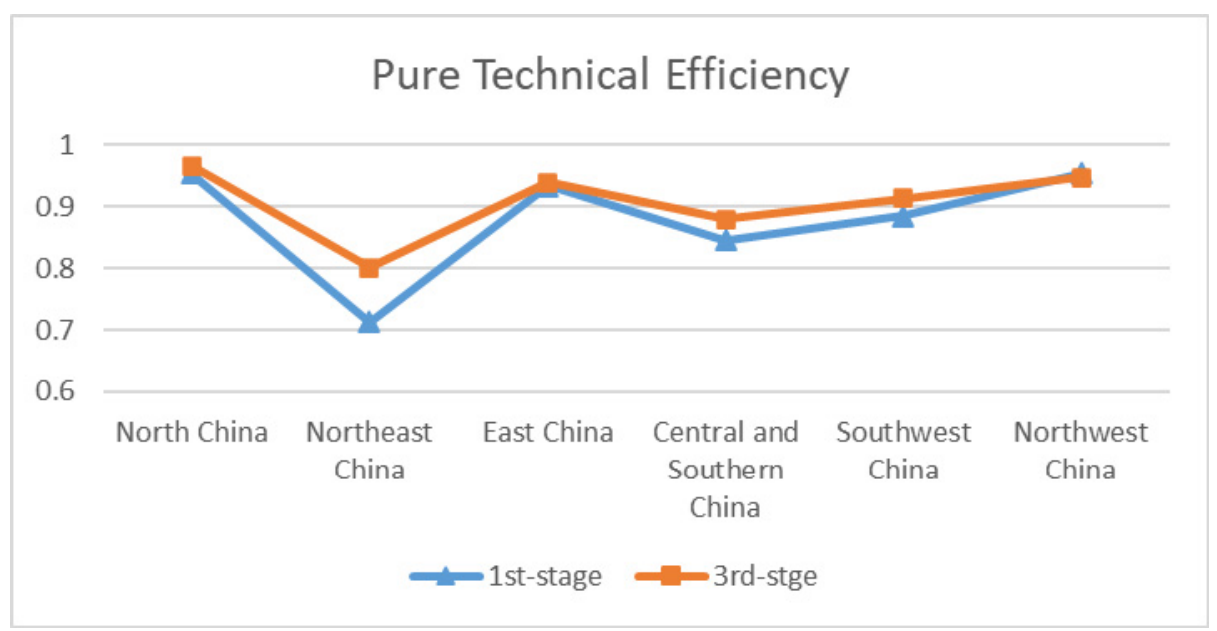

(a)

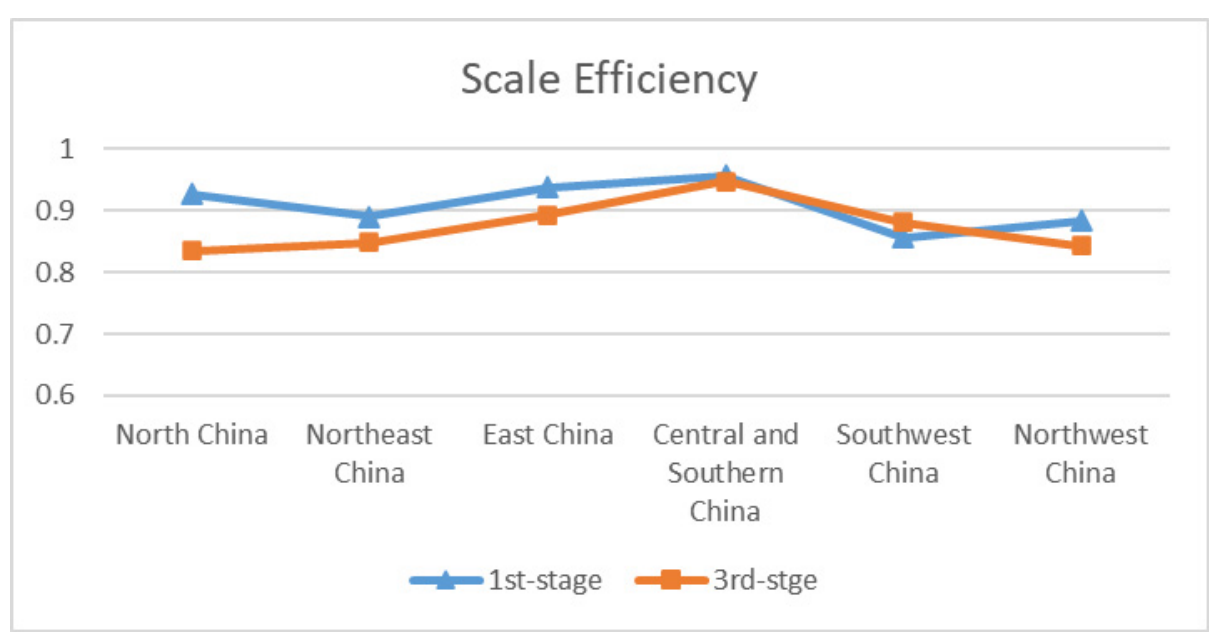

(b)

Figure 2. (a) Pure technical efficiency (PTE) estimation results of six regions at the first and third stages; (b) scale efficiency (SE) estimation results of six regions at the first and third stages.

As shown in Figure 2 and Table 5, at the third stage, after the separation of environmental effects and statistical noise, North China, East China, and Northwest China have relatively high PTE (0.9596, 0.9387, and 0.9474, respectively). However, North China and Northwest China have the lowest SE values ( 0.8348 and 0.8424 , respectively). Meanwhile, most of the provinces in these two regions are at the stage of increasing returns to scale (4 IRS and 1 CRS in the 5 DMUs of North China; 3 IRS and 2 CRS in the 5 DMUs of Northwest China). Operating at IRS means that a more than proportional increase in outputs can be gained given an increase in inputs, while operating at DRS means that a less than proportional increase in outputs can be gained given an increase in inputs. Therefore this result indicates that most provincial ATSs in these two regions are operating at too small a scale and could gain enhancement by moving towards the scale-efficient size under the currently available technology. That is to say, the North China and Northwest regions can adopt an expansionary strategy in ATS development to improve the returns to scale, under the premise of not making currently technically efficient provinces fall into an inefficient condition. 
Table 5. PTE (pure technical efficiency) and SE (scale efficiency) estimation results of six regions in China.

\begin{tabular}{ccccc}
\hline Rank & PTE & \multicolumn{2}{c}{ SE } \\
\hline 1 & North China & 0.9656 & Central and Southern China & 0.9477 \\
2 & Northwest China & 0.9474 & East China & 0.8933 \\
3 & East China & 0.9387 & Southwest China & 0.8810 \\
4 & Southwest China & 0.9128 & Northeast China & 0.8487 \\
5 & Central and Southern China & 0.8797 & Northwest China & 0.8424 \\
6 & Northeast China & 0.8003 & North China & 0.8348 \\
\hline
\end{tabular}

The region of Central and Southern China has the highest scale efficiency (0.9477). However, among the six provinces in Central and Southern China, Hubei and Henan are at the stage of CRS, while Guangdong and Hainan are at the stage of DRS. Therefore, it would be sensible to be prudent in the expansion of the air transport industry and enhance the utilization of input resources.

The lowest ATS PTE (0.8003) exists in Northeast China. Although Liaoning, Jilin, and Heilongjiang are all at the stage of IRS, authorities in this region should put an emphasis on technical progress, management improvement, and productivity increase in the air transport industry instead of mass additional expansion in scale, in order to ensure the ATS efficiency and sustainability in the long run. PTE and SE values in Southwest China are in the middle level. Resources input into this region's ATS and its output also maintain a relatively balanced state. However, due to the remote geographical location plus complex topographic features in Southwest China provinces (Sichuan, Yunnan, Guizhou), a large number of airports has been built in this region. Sichuan and Yunnan operate with DRS, and Guizhou has the lowest PTE in 30 provinces. Thus, it is necessary for Southwest China to optimize inputs utilization in Sichuan and Yunnan, and improve management and technical efficiency in Guizhou.

\section{Discussion}

The operational performance evaluation of ATS is not only determined by controllable inputs, but also affected by the exterior economic and social environment and statistical noise. To overcome the drawbacks of the traditional deterministic DEA method, this study applied a three-stage model to evaluate provincial ATS operational performance. This model takes variable measurement errors and unobserved but potentially relevant variables into consideration by using a stochastic disturbance term in SFA. Meanwhile, features of the operating environment are taken into consideration by the introduction of environmental variables.

Five socio-economic indicators were selected as environmental variables. In order to more accurately measure the resource input and evaluate the operational performance, a perpetual inventory method was used to calculate the capital stock of the air transport sector, and the index of infrastructure construction level (ICL) of each province was constructed.

Coefficients that are significant at the $1 \%$ confidence level in the SFA model at the second stage illustrate that environmental variables indeed have critical influences on the input slacks and therefore on the operational efficiency of provincial ATSs. After adjustment for the influence of environmental factors and statistical noise, the average PTE and SE values computed in the third stage DEA were 0.916 and 0.880 , respectively. The different efficiency evaluation value variations of different provinces before and after the adjustment indicate that the socio-economic environment conditions for ATS operation are different among provinces.

The PTE and SE values of six regions show us the provincial ATS efficiency differences. North China and Northeast China have the highest and lowest PTE, respectively. Central and Southern China has the highest scale efficiency, while North China has the lowest scale efficiency. Meanwhile PTE and SE values in Southwest China are in the middle level. 
The returns to scale analysis show significant differences between stage 1 and stage 3 results. North China and the Northwest region can adopt an expansionary strategy in ATS development to improve the returns to scale.

The above results can help us get an accurate evaluation of provincial ATS operational performance excluding exterior environmental variations. A specific direction to improve operational performance of provincial ATSs is also gained as previously mentioned. Additionally, it can also contribute to the feasibility research of national and regional air transport sector investment decisions. Although the air transport sector of China is taken as an example in this study, the three-stage DEA-based model and the research process can be applied to efficiency evaluation studies among different regions, due to the similarity of the relations between air transportation and regional socio-economic environments all over the world.

Author Contributions: Conceptualization, data, G.J., M.S.; methodology, software, writing—original draft preparation, M.S.; writing — review and editing, P.Z.; supervision, G.J.; funding acquisition, G.J. All authors have read and agreed to the published version of the manuscript.

Funding: This research is funded by interdisciplinary and innovative international training program of Tongji University, grant number 2020XKJC-005.

Conflicts of Interest: The authors declare no conflict of interest.

\section{References}

1. Tanzi, V.; Schuknecht, L. Reconsidering the Fiscal Role of Government: The International Perspective. Am. Econ. Rev. 1997, 87, 164-168. Available online: www.jstor.org/stable/2950906 (accessed on 23 April 2020).

2. Afonso, A.; Schuknecht, L.; Tanzi, V. Public sector efficiency: Evidence for new EU member states and emerging markets. Appl. Econ. 2010, 42, 2147-2164. [CrossRef]

3. Catalano, G.; Daraio, C.; Diana, M.; Gregori, M.; Matteucci, G. Efficiency, effectiveness, and impacts assessment in the rail transport sector: A state-of-the-art critical analysis of current research. Int. Trans. Oper. Res. 2019, 26, 5-40. [CrossRef]

4. Örkcü, H.H.; Balıkçı, C.; Dogan, M.I.; Genç, A. An evaluation of the operational efficiency of turkish airports using data envelopment analysis and the Malmquist productivity index: 2009-2014 case. Transp. Policy 2016, 48, 92-104. [CrossRef]

5. Lozano, S.; Gutiérrez, E.; Moreno, P. Network DEA approach to airports performance assessment considering undesirable outputs. Appl. Math. Model. 2013, 37, 1665-1676. [CrossRef]

6. Liu, D. Measuring aeronautical service efficiency and commercial service efficiency of East Asia airport companies: An application of Network Data Envelopment Analysis. J. Air Transp. Manag. 2016, 52, 2-14. [CrossRef]

7. Duygun, M.; Prior, D.; Shaban, M.; Tortosa-Ausina, E. Disentangling the European airlines efficiency puzzle: A network data envelopment analysis approach. Omega-Int. J. Manag. Sci. 2016, 60, 2-14. [CrossRef]

8. Cui, Q.; Li, Y. Airline efficiency measures under CNG2020 strategy: An application of a Dynamic By-production model. Transp. Res. Part A Policy Pract. 2017, 106, 130-143. [CrossRef]

9. Zhou, Y.M.; Wang, J.W.; Huang, G.Q. Efficiency and robustness of weighted air transport networks. Transp. Res. Part E Logist. Transp. Rev. 2019, 122, 14-26. [CrossRef]

10. Cardillo, A.; Zanin, M.; Gómez-Gardeñes, J.; Romance, M.; García del Amo, A.J.; Boccaletti, S. Modeling the multi-layer nature of the European Air Transport Network: Resilience and passengers re-scheduling under random failures. Eur. Phys. J. Spec. Top. 2013, 215, 23-33. [CrossRef]

11. Huang, E.; Liu, I.; Lin, J.T. Robust model for the assignment of outgoing flights on airport baggage unloading areas. Transp. Res. Part E Logist. Transp. Rev. 2018, 115, 110-125. [CrossRef]

12. Bilotkach, V.; Gitto, S.; Mancuso, P. Introduction to special issue "Efficiency and productivity in the air transport industry". Res. Transp. Econ. 2016, 56, 1-2. [CrossRef]

13. Miyoshi, C.; Mason, K.; Martini, G. Enhancing the network efficiency: Air transport and sustainability. J. Air Transp. Manag. 2018, 69, 213-214. [CrossRef]

14. Abbott, M.; Wu, S. Total factor productivity and efficiency of Australian airports. Aust. Econ. Rev. 2002, 35, 244-260. [CrossRef] 
15. Barros, C.P.; Dieke, P.U.C. Measuring the economic efficiency of airports: A Simar-Wilson methodology analysis. Transp. Res. Part E Logist. Transp. Rev. 2008, 44, 1039-1051. [CrossRef]

16. Chaouk, M.; Pagliari, D.R.; Moxon, R. The impact of national macro-environment exogenous variables on airport efficiency. J. Air Transp. Manag. 2020, 82, 101740. [CrossRef]

17. Ülkü, T. A comparative efficiency analysis of Spanish and Turkish airports. J. Air Transp. Manag. 2015, 46, 56-68. [CrossRef]

18. Fried, H.O.; Lovell, C.A.K.; Schmidt, S.S.; Yaisawarng, S. Accounting for Environmental Effects and Statistical Noise in Data Envelopment Analysis. J. Prod. Anal. 2002, 17, 157-174. [CrossRef]

19. Shang, J.-K.; Hung, W.-T.; Lo, C.-F.; Wang, F.-C. Ecommerce and hotel performance: Three-stage DEA analysis. Serv. Ind. J. 2008, 28, 529-540. [CrossRef]

20. Shang, J.-K.; Hung, W.-T.; Wang, F.-C. Service outsourcing and hotel performance: Three-stage DEA analysis. Appl. Econ. Lett. 2008, 15, 1053-1057. [CrossRef]

21. Shyu, J.; Chiang, T. Measuring the true managerial efficiency of bank branches in Taiwan: A three-stage DEA analysis. Expert Syst. Appl. 2012, 39, 11494-11502. [CrossRef]

22. Zeng, S.; Hu, M.; Su, B. Research on Investment Efficiency and Policy Recommendations for the Culture Industry of China Based on a Three-Stage DEA. Sustainability 2016, 8, 324. [CrossRef]

23. Zhao, H.; Zhao, H.; Guo, S. Operational Efficiency of Chinese Provincial Electricity Grid Enterprises: An Evaluation Employing a Three-Stage Data Envelopment Analysis (DEA) Model. Sustainability 2018, 10, 3168. [CrossRef]

24. Li, K.; Lin, B. Impact of energy conservation policies on the green productivity in China's manufacturing sector: Evidence from a three-stage DEA model. Appl. Energy 2016, 168, 351-363. [CrossRef]

25. Chen, Y.; Liu, B.; Shen, Y.; Wang, X. The energy efficiency of China's regional construction industry based on the three-stage DEA model and the DEA-DA model. Ksce J. Civ. Eng. 2016, 20, 34-47. [CrossRef]

26. Cui, Q.; Li, Y. The evaluation of transportation energy efficiency: An application of three-stage virtual frontier DEA. Transp. Res. Part D Transp. Environ. 2014, 29, 1-11. [CrossRef]

27. Zhao, C.; Zhang, H.; Zeng, Y.; Li, F.; Liu, Y.; Qin, C.; Yuan, J. Total-Factor Energy Efficiency in BRI Countries: An Estimation Based on Three-Stage DEA Model. Sustainability 2018, 10, 278. [CrossRef]

28. Fried, H.O.; Schmidt, S.S.; Yaisawarng, S. Incorporating the Operating Environment into a Nonparametric Measure of Technical Efficiency. J. Prod. Anal. 1999, 12, 249-267. [CrossRef]

29. Fang, C.Y.; Hu, J.L.; Lou, T.K. Environment-adjusted total-factor energy efficiency of Taiwan's service sectors. Energy Policy 2013, 63, 1160-1168. [CrossRef]

30. Banker, R.D.; Charnes, A.; Cooper, W.W. Some Models for Estimating Technical and Scale Inefficiencies in Data Envelopment Analysis. Manag. Sci. 1984, 30, 1078-1092. [CrossRef]

31. Charnes, A.; Cooper, W.W.; Rhodes, E. Measuring the efficiency of decision making units. Eur. J. Oper. Res. 1978, 2, 429-444. [CrossRef]

32. Banker, R.D.; Thrall, R.M. Estimation of returns to scale using data envelopment analysis. Eur. J. Oper. Res. 1992, 62, 74-84. [CrossRef]

33. Jondrow, J.; Knox Lovell, C.A.; Materov, I.S.; Schmidt, P. On the estimation of technical inefficiency in the stochastic frontier production function model. J. Econom. 1982, 19, 233-238. [CrossRef]

34. Irmen, A.; Kuehnel, J. Productive Government Expenditure and Economic Growth. J. Econ. Surv. 2009, 23, 692-733. [CrossRef]

35. Maparu, T.S.; Mazumder, T.N. Transport infrastructure, economic development and urbanization in India (1990-2011): Is there any causal relationship? Transp. Res. Part A Policy Pract. 2017, 100, 319-336. [CrossRef]

36. Crescenzi, R.; Di Cataldo, M.; Rodriguez-Pose, A. Government Quality and The Economic Returns of Transport Infrastructure Investment in European Regions. J. Reg. Sci. 2016, 56, 555-582. [CrossRef]

37. Young, A. Gold into base metals: Productivity growth in the People's Republic of China during the reform period. J. Polit. Econ. 2003, 111, 1220-1261. [CrossRef]

38. Kamps, C. New estimates of government net capital stocks for 22 OECD countries, 1960-2001. IMF Staff Pap. 2006, 53, 120-150.

39. Zhang, J. Estimation of China's provincial capital stock (1952-2004) with applications. J. Chin. Econ. Bus. Stud. 2008, 6, 177-196. [CrossRef]

40. Jin, G. The Estimation of China's Infrastructure Capital Stock. Econ. Res. J. 2012, 47, 12. 
41. Jin, G. Infrastructure and Non-infrastructure Capital Stocksin China and Their Productivity: A New Estimate. Econ. Res. J. 2016, 51, 16.

42. De Barros, A.G.; Wirasinghe, S.C. Designing the airport airside for the new large aircraft. J. Air Transp. Manag. 2002, 8, 121-127. [CrossRef]

43. Chang, Y.-T.; Zhang, N.; Danao, D.; Zhang, N. Environmental efficiency analysis of transportation system in China: A non-radial DEA approach. Energy Policy 2013, 58, 277-283. [CrossRef]

44. Liu, X.H.; Wu, J. Energy and environmental efficiency analysis of China's regional transportation sectors: A slack-based DEA approach. Energy Syst. 2017, 8, 747-759. [CrossRef]

45. Park, Y.S.; Lim, S.H.; Egilmez, G.; Szmerekovsky, J. Environmental efficiency assessment of US transport sector: A slack-based data envelopment analysis approach. Transp. Res. Part D Transp. Environ. 2018, 61, 152-164. [CrossRef]

46. Chi, J.; Baek, J. Price and income elasticities of demand for air transportation: Empirical evidence from US airfreight industry. J. Air Transp. Manag. 2012, 20, 18-19. [CrossRef]

47. Schuckmann, S.W.; Gnatzy, T.; Darkow, I.-L.; von der Gracht, H.A. Analysis of factors influencing the development of transport infrastructure until the year 2030-A Delphi based scenario study. Technol. Forecast. Soc. Chang. 2012, 79, 1373-1387. [CrossRef]

48. Xiao, Y.; Fu, X.; Zhang, A. Demand uncertainty and airport capacity choice. Transp. Res. Part B Methodol. 2013, 57, 91-104. [CrossRef]

49. Yao, S.J.; Yang, X.Y. Air transport and regional economic growth in China. Asia Pac. J. Acc. Econ. 2012, 19, 318-329. [CrossRef]

50. Debbage, K.G. Air transportation and urban-economic restructuring: Competitive advantage in the US Carolinas. J. Air Transp. Manag. 1999, 5, 211-221. [CrossRef]

51. Baker, D.; Merkert, R.; Kamruzzaman, M. Regional aviation and economic growth: Cointegration and causality analysis in Australia. J. Transp. Geogr. 2015, 43, 140-150. [CrossRef]

52. Balsalobre-Lorente, D.; Driha, O.M.; Bekun, F.V.; Adedoyin, F.F. The asymmetric impact of air transport on economic growth in Spain: Fresh evidence from the tourism-led growth hypothesis. Curr. Issues Tour. 2019, 24, 36-53. [CrossRef]

53. Khan, S.A.R.; Dong, Q.L.; Wei, S.B.; Zaman, K.; Zhang, Y. Travel and tourism competitiveness index: The impact of air transportation, railways transportation, travel and transport services on international inbound and outbound tourism. J. Air Transp. Manag. 2017, 58, 125-144. [CrossRef]

54. Halpern, N.; Bråthen, S. Impact of airports on regional accessibility and social development. J. Transp. Geogr. 2011, 19, 1145-1154. [CrossRef]

55. Bråthen, S.; Halpern, N. Air transport service provision and management strategies to improve the economic benefits for remote regions. Res. Transp. Bus. Manag. 2012, 4, 3-12. [CrossRef]

56. Butler, T.W.; Li, L. The utility of returns to scale in DEA programming: An analysis of Michigan rural hospitals. Eur. J. Oper. Res. 2005, 161, 469-477. [CrossRef]

(C) 2020 by the authors. Licensee MDPI, Basel, Switzerland. This article is an open access article distributed under the terms and conditions of the Creative Commons Attribution (CC BY) license (http://creativecommons.org/licenses/by/4.0/). 